\title{
A participação dos homens na alimentação infantil: novos caminhos para a equidade de gênero?
}

\section{The participation of men in infant feeding: is this a new step towards gender equity?}

\author{
Elizabeth Sorrentino ${ }^{\mathrm{a}}$ \\ (i) https://orcid.org/0000-0002-0308-7602 \\ E-mail: elizabethsionळuol.com.br

\section{Cláudia Maria Bógus ${ }^{b}$} \\ (D) https://orcid.org/0000-0003-0925-2741 \\ E-mail: claudiab®usp.br

\section{Sonia Venancioc} \\ (D) https://orcid.org/0000-0001-7147-3292 \\ E-mail: soniavœisaude.sp.gov.br \\ a Universidade de São Paulo. Faculdade de Saúde Pública. \\ Departamento de Nutrição. São Paulo, SP, Brasil.

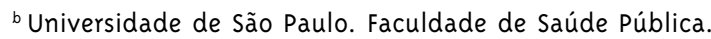 \\ Departamento de Política, Gestão e Saúde. São Paulo, SP, Brasil. \\ 'Instituto de Saúde, Secretaria de Estado da Saúde de São Paulo. \\ Centro de Tecnologias de Saúde. São Paulo, SP, Brasil.
}

\section{Correspondência}

Elizabeth Sorrentino

Universidade de São Paulo. Faculdade de Saúde Pública. Av. Doutor Arnaldo, 715. São Paulo, SP, Brasil. CEP 01246-904.

\section{Resumo}

Este estudo objetivou compreender a vivência de homens na alimentação dos seus filhos entre 6 e 12 meses de idade, com a finalidade de contribuir para a agenda de políticas públicas em programas de educação nutricional voltados para o desenvolvimento da primeira infância. A abordagem qualitativa apoiada pelo método hermenêutico-dialético, através de grupos focais com mães e entrevistas em profundidade com pais, frequentadores de um serviço público de saúde e de uma clínica de pediatria privada, permitiu compreender o tema sob circunstâncias socioeconômicas diferentes e organizá-los em duas categorias: a participação do gênero masculino na alimentação de seus filhos sob a ótica feminina e sob a sua própria ótica. Nos deparamos, nos resultados, com a complexidade como se move o fenômeno, fruto de uma rede de interações entre os indivíduos, seus valores e sua relação com o mundo presente. As expressões simbólicas reproduziram os valores tradicionais que norteiam tanto as crenças femininas quanto masculinas. Destaca-se, entretanto, o movimento de transformação nas atitudes de compartilhamento e envolvimento paterno com a alimentação dos filhos.

Palavras-chave: Nutrição da Criança; Alimentação Complementar; Questões de Gênero. 


\section{Introdução}

Our study investigates men's experience in feeding their children aged from six to 12 months aiming at contributing to the public policy agenda in nutritional education programs focused on early childhood development. The qualitative approach was substantiated by the hermeneutic-dialectical method, based on focus groups with mothers and on in-depth interviews with parents and visitors to public health services and private pediatric clinics. It allowed understanding the investigated topic under different socioeconomic circumstances and organizing them into two categories, namely: male participation in feeding their children, based on both women's and their own point of view. Results evidenced the complexity of the phenomenon, which is the result from a network of interactions among individuals, their values and their relationship with the present world. Symbolic expressions have reproduced the traditional values, guiding both female and male beliefs. However, the transformation in paternal attitudes towards sharing and getting involved in feeding their children stood out.

Keywords: Child Nutrition; Complementary Feeding; Gender Issues.
A importância da alimentação da criança, principalmente nos seus primeiros anos de vida, está fartamente documentada e seu impacto inserido em vários relatórios internacionais de políticas de saúde (WHO, 2010; USAID, 2011; UNICEF, 2020), com destaque para os guias alimentares voltados à população infantil (Brasil, 2019). Se adequada nos primeiros mil dias de vida da criança, influenciará o pleno desenvolvimento deste indivíduo em todas as fases da vida (USAID, 2011), fará parte da prevenção de agravos e de doenças na fase adulta e poderá contribuir para uma vida ativa (Victora et al., 2016; Pérez-Escamilla; Segura-Pérez; Lott, 2017), necessária ao digno enfrentamento do processo de envelhecimento, outro grande desafio para a agenda de políticas públicas.

Apesar das evidências sobre sua importância, estudos nacionais e internacionais observaram que a alimentação complementar, definida como a alimentação oferecida às crianças após o sexto mês de vida em complemento ao leite materno (Victora et al., 2016), é de baixa qualidade (Jaime et al., 2016; UNICEF, 2019) e sua implementação depende do conhecimento daqueles que se ocupam dos cuidados infantis (Pérez-Escamilla; Segura-Pérez; Lott, 2017; Pérez-Escamilla; Segura-Pérez, 2019). As intervenções nutricionais buscam influenciar e aprimorar comportamentos positivos para dar às crianças um melhor começo de vida e estão focadas especialmente na figura materna. É sabido, porém, que o incentivo ao envolvimento ativo de homens em ações que apoiaram as mães nos cuidados com seus filhos melhorou os resultados em saúde (Addati; Cassirer; Gilchrist, 2014), enfatizando a importância da contribuição paterna como um potencial facilitador a adoção de práticas saudáveis de alimentação de bebês e crianças pequenas (Addati; Cassirer; Gilchrist, 2014; Pérez-Escamilla; Segura-Pérez; Lott, 2017).

A definição de paternidade, hoje, abrange muitas das atividades vistas como "tipicamente femininas" (Lamb, 2010; Figueiredo; Diniz, 2018), no entanto, estas mudanças de comportamento parecem não se concretizar em quantidade e qualidade que acompanhem satisfatoriamente o ritmo das mudanças sociais (Jablonski, 2010; Figueiredo; 
Diniz, 2018). Apesar dos pais estarem realizando mais tarefas domésticas e cuidados infantis e das mães realizarem mais trabalho remunerado fora de casa, nenhum deles ultrapassou o outro em seus domínios "tradicionais" (Parker; Wang, 2013; Figueiredo; Diniz, 2018) e, quando se trata daquilo que mais valorizam, para os pais é mais importante ter um emprego com altos salários, enquanto as mães empregadas estão mais preocupadas em ter horários flexíveis (Parker; Wang, 2013).

A passagem dos homens para o "novo modelo" de paternidade (Sutter; Bucher-Maluschke, 2008), especialmente provocado pelo nascimento de um filho (Freitas; Coelho; Silva, 2007), e sua participação efetiva como cuidador têm sido relativamente negligenciadas pela investigação, mas quando estudadas, revelam semelhanças e diferenças do gênero nessas experiências, que importaria aprofundar por perpassarem não só as relações pessoais, mas igualmente as sociais e institucionais (Ribeiro; Gomes; Moreira, 2015). No Brasil, estudos chamam a atenção para o fato de que a sensibilização pelo "cuidado" diz respeito não somente aos homens, mas também aos profissionais da saúde, especialmente na atenção primária, que muitas vezes ignoram a participação paterna no pré-natal, parto e consultas pediátricas (Ribeiro; Gomes; Moreira, 2015).

Lacunas de conhecimento e informação de mães e pais, além de barreiras socioculturais e institucionais fortemente marcadas por crenças e mitos, influenciam e comprometem a prestação de cuidados à criança (Ribeiro; Gomes; Moreira, 2015; Pérez-Escamilla; Segura-Pérez; Lott, 2017; Sorrentino; Venancio, 2019; Brasil, 2019).

Assim, esta pesquisa apresenta relevância em função de sua originalidade ao refletir sobre o papel masculino e a divisão de tarefas durante o primeiro ano de vida de seus filhos, com foco na alimentação sob a ótica feminina e masculina em condições socioeconômicas diversas. Nossa hipótese subentende que a compreensão do fenômeno poderia aprimorar a condução dessa importante abordagem, especialmente em intervenções de educação alimentar e nutricional (Pérez-Escamilla; Segura-Pérez; Lott, 2017) a fim de atender e fortalecer as políticas voltadas à promoção da nutrição e do desenvolvimento da primeira infância (Brasil, 2019).

\section{Percurso metodológico}

Optamos por uma abordagem de natureza qualitativa, por se preocupar com a compreensão interpretativa da ação social (Minayo; Assis; Souza, 2016) e por incluir todo o comportamento humano, levando em conta a inteligibilidade dos fenômenos sociais, seus significados e a intencionalidade que lhe atribuem os atores (Minayo; Assis; Souza, 2016). Seu foco é a experiência humana e a complexidade desta realidade (Minayo, 2008).

Como referencial teórico, elegemos o método de análise hermenêutico-dialético, cuja combinação de abordagens é "bastante produtiva para fundamentar as avaliações qualitativas” (Minayo; Assis; Souza, 2016, p. 88). Analisando as duas correntes filosóficas, Minayo (2008) e Minayo, Assis e Souza (2016) ressaltam suas contribuições e limitações, que em articulação, se complementam a favor da compreensão e da crítica da realidade social:

Enquanto a práxis hermenêutica assentada no presente, penetra no sentido do passado, da tradição, do outro, do diferente, buscando alcançar o sentido das mais diversas formas de texto, a dialética se dirige contra seu tempo. Enfatiza a diferença, o contraste, a dissensão e a ruptura do sentido. (Minayo, 2008, p. 105)

Nesta perspectiva, foram utilizados como instrumentos técnicos para a construção das investigações o grupo focal e a entrevista aberta ou em profundidade (Minayo, 2008).

A produção de dados através de grupo focal envolveu dois grupos de mães de crianças entre 6 e 12 meses, recrutadas em duas localidades com características socioeconômicas diversas, a fim de se conhecer o tema estudado sob circunstâncias e contextos diferentes. No primeiro estudo, nominado G1 e ocorrido no dia 2 de abril de 2018 , oito participantes formaram o grupo recrutado na Unidade Básica de Saúde Jardim Esperança, em Francisco Morato, município localizado na Grande São Paulo. Para o outro, aqui nominado G2, recrutado na clínica privada Casa Curumim, no bairro Sumarezinho, Zona Oeste da capital paulista, foram contatadas inicialmente 12 mães, dentre as quais, 
oito confirmaram a possibilidade da presença para o dia 24 de março de 2018 , sendo que destas, quatro compareceram. Ambos os encontros ocorreram nos locais do recrutamento.

Para permitir a conexão entre os objetivos da pesquisa e os grupos focais, utilizou-se um roteiro semiestruturado em tópicos que propiciasse aos participantes a oportunidade de revelarem suas perspectivas livremente. Testado previamente numa situação piloto, contemplou aspectos relacionados ao momento em que os cuidadores iniciaram a alimentação complementar, suas dúvidas, dificuldades e o tipo de apoio recebido. Nos encontros, que tiveram uma duração média de 90 minutos, a pesquisadora assumiu o papel de moderadora e contou com auxílio de uma assistente. Os relatos foram gravados em sistema áudio de forma a preservar a fidelidade das opiniões (Mack et al., 2011) somente após o consentimento dos participantes.

Para compreender os processos de vivência e participação masculina na alimentação complementar dos seus filhos entre 6 e 12 meses de idade, inicialmente tentamos promover grupos focais com homens. Como não obtivemos adesão em número suficiente, optamos por realizar entrevistas abertas, técnica que também oferece a oportunidade de conhecer como as pessoas interpretam e ordenam um determinado assunto a partir de suas opiniões e experiências (Minayo; Assis; Souza, 2016).

A condição para o recrutamento foi a de que os participantes fossem pais de crianças de 6 a 12 meses de idade. Dois deles com filhos frequentadores da UBS Jardim Esperança em Francisco Morato, aqui nominados E1, e os outros dois, aqui nomeados E2, com filhos atendidos na clínica de pediatria privada Curumim, em São Paulo, contextualizando, assim, as impressões masculinas em duas realidades socioeconômicas diversas.

As entrevistas ocorreram nos locais do recrutamento. As realizadas com os pais de Francisco Morato, nos dias 27 e 28 de abril de 2018, e as com os sediados na capital, no dia 5 de maio, individualmente, uma às 10 h e a outra às 11h. Estes últimos, coincidentemente, eram pais de crianças cujas mães haviam participado do grupo focal, o que nos permitiu um exercício de reflexão, que os acontecimentos são interdependentes e se condicionam uns aos outros, podendo originar um comportamento novo (Minayo; Assis; Souza, 2016).

O instrumento para a produção de dados, previamente testado, constituiu-se de um roteiro com questões abertas à semelhança do roteiro dos grupos focais, permitindo que os participantes se expusessem livremente. As entrevistas foram conduzidas pela mesma pesquisadora que moderou os grupos focais, também com o auxílio de uma assistente. A duração média das entrevistas foi de 20 minutos, registradas no sistema áudio e posteriormente transcritas.

A análise dos dados a partir da transcrição meticulosa das gravações e da leitura de todo o material contemplou dois momentos complementares: a análise específica de cada grupo, pré-análise (Mack et al., 2011), na qual agrupamos todo o conteúdo pelas falas de cada participante e a análise cumulativa e comparativa do conjunto de grupos e entrevistas realizadas (Minayo; Assis; Souza, 2016). Esta exploração exigiu que lêssemos e relêssemos cada depoimento, nos possibilitando grande intimidade com o conteúdo tanto objetiva quanto intersubjetiva (Minayo, 2008). A riqueza dos depoimentos sobre o papel masculino na divisão de tarefas durante o primeiro ano de vida de seus filhos, com foco na alimentação, nos levou a considerar, apresentálos de maneira única, separando-os dos demais aspectos abordados no roteiro/guia (Sorrentino; Venancio, 2019), organizando-os em duas categorias (Minayo; Assis; Souza, 2016): a participação masculina na alimentação de seus filhos sob a ótica feminina e sob a sua própria ótica. As condições socioeconômicas dos participantes não receberam neste estudo uma classificação formal e, apesar de estarem diferenciados pelas siglas $\mathrm{G}_{1} / \mathrm{E}_{1}$ e $\mathrm{G}_{2} / \mathrm{E}_{2}$, preferimos apreciar seus relatos como representações naturais, cada qual de seu mundo social (Carvalho; Luz, 2009). Cabe aqui mencionar que a coleta de informações sobre um mesmo fenômeno, provenientes de indivíduos, estratégias e ambientes diversificados, apesar de não garantir a validade, reduz o risco de associações de acaso e de vieses sistemáticos por permitir maior generalidade a favor da avaliação e das inferições (Minayo; Assis; Souza, 2016).

Em sequência a esta etapa, procuramos buscar as ideias além das falas e dos fatos descritos e 
aprofundá-las através das seguintes reflexões (Minayo; Assis; Souza, 2016): as ideias se diferenciaram por fatores como gênero ou condições socioeconômicas? Quais os pontos comuns entre os depoimentos? Houve contradições? Há dados que nos permitam comparar os argumentos ou as ideias entre as duas categorias? Há informações de outros estudos sobre o tema que reforçam ou contradizem as ideias subjacentes as falas?

Este caminho de prática à interpretação se constituiu em um exercício para ultrapassar os níveis descritivos, constructo de primeira ordem (Minayo; Assis; Souza, 2016), acessar a inferência e se chegar à interpretação propriamente dita (constructo de segunda ordem), que, de acordo com Minayo; Assis; Souza, 2016, é um “ônus que cabe ao investigador" (p. 203).

Aconstrução da síntese interpretativa foi ancorada pelo aporte de vários estudiosos que exploram a paternidade e a complexa relação de equidade entre homens e mulheres (Szinovacz, 1984; Zagury, 2002; Balancho, 2004; Hakim, 2005; Jablonski, 2010; Vega-Robles, 2007; Sutter; Bucher-Maluschke, 2008; Aboim, 2010; Parker; Wang, 2013; Ribeiro; Gomes; Moreira, 2015; Figueiredo; Diniz, 2018), além de estudos que nos levaram a refletir sobre as dificuldades em interpretar sentidos e significados culturais (Dilts; Hallbom; Smith, 1993) construídos com base nas práticas de saúde (Carvalho; Luz, 2009).

Obedecendo à exigência da Resolução $n^{\circ}$ 510/2016 do Conselho Nacional de Saúde, que dispõe sobre as normas aplicáveis a pesquisas em ciências humanas e sociais, a presente pesquisa foi submetida ao comitê de Ética da Faculdade de Saúde Pública, recebendo aprovação CAAE:78929317.7.ooo.5421 através do parecer número $2 \cdot 358.135$.

\section{Resultados e discussão}

É importante que ressaltemos que, mesmo inicialmente, quando previmos um montante de participantes tanto para os grupos focais quanto para as entrevistas, a ideia de provisoriedade nos acompanhou durante todo o processo (Minayo, 2017). Conscientes de que o principal critério não é o numérico "pois não há medida estabelecida a priori para o entendimento das homogeneidades, da diversidade e da intensidade das informações necessárias a um adequado trabalho de pesquisa" (Minayo, 2017, p. 11), buscamos o aprofundamento, a abrangência e a diversidade no processo de compreensão, no intuito de acessar a lógica interna do objeto de estudo em todas as suas conexões e interconexões (Minayo, 2017).

Entre as participantes dos dois grupos focais, o grau de escolaridade foi maior no G2, no qual todas possuíam nível superior completo. No G1, a maioria havia concluído o ensino médio. Em relação à distribuição etária, a idade do G1 variou entre $21 \mathrm{e}$ 30 anos e metade relatou ter outros filhos. Já no G2, todas eram primíparas, com idade entre 29 e 37 anos. No G1, apenas uma das mães possuía trabalho extradomiciliar, enquanto no $\mathrm{G}_{2}$, todas relataram atividades profissionais formais.

Entre os entrevistados, tanto os do E1 quanto do E2, a idade era homogênea, variando entre 34 e 35 anos. Todos possuíam empregos formais, sendo que no E1, suas cargas horárias os permitiam estar mais próximos dos filhos. Observou-se, entre os dois grupos, diferenças com relação ao grau de escolaridade: maior para o E2 (ensino superior completo e incompleto) e menor para o E1 (ensino médio completo e incompleto). Coincidentemente, ambos os pais do E1 relataram ter outro filho entre 13 e 14 anos. Para os pais do E2, tratava-se da primeira paternidade.

\section{A participação masculina na alimentação de seus filhos sob a ótica feminina}

As mulheres do G1 quando indagadas sobre “apoio" dos companheiros, imediatamente compreenderam se tratar de apoio material e financeiro. É interessante se apreciar, apesar das grandes mudanças sociais, o enfoque feminista resultante de uma cultura extemporânea que resiste (Dilts; Hallbom; Smith, 1993; Minayo, 2008). Quando abrimos mais a pergunta, especulando se recebiam ajuda nas tarefas domésticas e com os cuidados com os filhos, o que permeou todas as falas foi a constatação de que o pai e sua imagem continuam associados à função tradicional de provedor (Sutter; Bucher-Maluschke, 2008). 
[...] por parte do meu esposo, ele tem muito receio de fazer as coisas... Então ele compra, mas fala: é você quem vai dar. (K G1)

O meu apoia também, ele vai lá e compra as coisa. Mas pra fazer, não faz não, porque diz que não sabe. Aí eu faço. (A Gì)

o pai dela, da S, a gente mora junto. Então quando está acabando as coisas, ele vai lá e compra. Tenho bastante apoio desde quando elas nasceram. (J G1)

Embora os depoimentos se refiram a experiências individuais, as representações de tais experiências não surgem somente das mentes individuais (Minayo; Assis; Souza, 2016). Em alguma medida, elas resultam de processos sociais (Dilts; Hallbom; Smith, 1993) através dos quais os indivíduos são culturalmente construídos (Minayo; Assis; Souza, 2016), já que necessitam se organizar em seu mundo (Carvalho; Luz, 2009). É sabido que o cuidado, seja com a própria saúde ou com o outro, são aspectos que não fazem parte do repertório masculino (Ribeiro; Gomes; Moreira, 2015) e, neste sentido, as tarefas domésticas e o cuidado infantil não são esferas masculinas (Sutter; BucherMaluschke, 2008). Prevalece, portanto, a matriz sócio-histórica que imputa à mãe o "autossacrifício" no cumprimento de sua reponsabilidade em garantir o bem-estar dos filhos e da família (Zagury, 2002; Aboim, 2010). "Eu acordo 2 vezes na noite porque ela quer tomar leite (mamadeira). Eu trabalho 12 horas [...], nossa é muito difícil (se emocionou)" (A G1).

Surge, porém, entre os depoimentos do mesmo grupo socioeconômico, a figura do colaborador, revelando que não há um consenso entre os comportamentos. $\mathrm{O}$ compartilhamento das tarefas denota um movimento de transformação nas atitudes (Minayo, 2008).

Ele (marido) me ajuda bastante; ajuda em casa, vai no mercado; faz a comida... quando eu estou limpando a casa. (AB G1)

Final de semana ele está em casa, ele fala: vou te dar uma folga. Quando está pronta a janta, o almoço, que ele mesmo faz, porque adora cozinhar, a gente senta na mesa e todo mundo come. (J G1)

Os relatos de $\mathrm{N}$ e M, representantes do outro grupo socioeconômico, nos revelam através da palavra "ajuda" e da expressão "vai ter que ser tudo dividido" que, apesar de ambos, pai e a mãe, aceitarem que as fronteiras entre eles se dissolveram e que cada membro pode e deve substituir o outro nos cuidados com os filhos, é da mãe o protagonismo como cuidadora (Parker; Wang, 2013). A sobrecarga materna é um fato que aproxima os indivíduos e os grupos analisados, independentemente da condição socioeconômica (Minayo, 2008).

Meu marido me apoia 10o\%. (Ele) ajuda na cozinha... ele tenta fazer o máximo parecido com o que eu faço. ( $\left.\mathrm{N} \mathrm{G}_{2}\right)$

Eu ainda não voltei a trabalhar, mas também trabalho, e ele (marido) sabe que vai ter que ser tudo dividido... (M G2)

Ser mãe e ser profissional é um exercício permeado pelo conflito diante da performance exigida em sua dupla jornada. 0 sentimento de culpa por não agirem de acordo com os papéis modelados e valorizados pela sociedade pode estar presente nas suas vivências (Zagury, 2002; Minayo, 2008).

Na escola ele comeu. No sábado fui preparar a comidinha do H... careta, chorava desesperado. $O$ que eu estou fazendo? ( $\left.\mathrm{N} \mathrm{G}_{2}\right)$

Voltei a trabalhar. Três vezes eu fico em casa cuidando dela e duas ela fica com a minha mãe. Eu tenho que preparar a comida dela. Vou lembrar dez minutos antes dela comer... a questão de eu trabalhar em casa e ter que oferecer pra ela, me dava muita insegurança. Eu tinha que meio que fazer ela comer naquele período, pra eu voltar a trabalhar e cumprir com meu compromisso. (B G2)

Na casa de B, ambos, marido e mulher, exercem uma atividade remunerada, porém, a divisão de tarefas ainda é tradicional ou não tão equilibrada. 
Estudos em sociedades modernas e socialmente desenvolvidas sugerem que as mudanças dependem de uma complexa relação entre família e outras estruturas sociais e não estão necessariamente determinados pela prosperidade socioeconômica (Hakim, 2005; Vega-Robles, 2007). Quando as coisas não caminham a contento, a mãe chega a acreditar que nada de errado aconteceria se ela estivesse mais presente (Zagury, 2002) e, em geral, quando não consegue conciliar os papeis profissional e materno, é comum que abdique da carreira (Aboim, 2010): "Esta semana eu pedi demissão porque não estava conseguindo ter a segurança de poder cuidar da minha filha nesta introdução alimentar" (B G2).

Tradicionalmente, é da mãe o dever de cuidar e alimentar; é ela quem deve dar conta das necessidades que se mostram diferentes a cada fase que o filho atravessa (Zagury, 2002). A, quando ouvida um mês antes do seu marido ser entrevistado, revelou que se sentia pressionada; era exigido de A uma mudança, um novo comportamento que ela não se sentia capaz de realizar por requerer aptidões que não dominava (Zagury, 2002; Aboim, 2010): "Me sinto totalmente insegura porque quase eu não cozinho nem pra mim" (A G2).

A conquista, pelas mulheres, de um universo produtivo não as exime do peso das responsabilidades que lhes são atribuídas simbólica e tradicionalmente pela família, surgindo então a resistência, a tensão e o conflito (Vega-Robles, 2007; Minayo, 2008).

[...] eu tenho um conflito com o meu marido na questão dos orgânicos. Minha mãe tentou me ajudar...ela via que eu não estava dando conta, só que ela faz a sopa com os legumes que tinha na casa dela. Meu marido bateu a porta e falou que não ia envenenar minha filha. Minha mãe falou: Se eu estou atrapalhando, não vou fazer mais nada. Aí a situação chegou num limite, que eu falei assim: você quer orgânico, então você compra toda semana. (A G2)

\section{A participação masculina na alimentação de seus filhos sob a sua própria ótica}

As falas de M (E2), um mês após o depoimento de A (G2), sua esposa, revelam que, a partir do conflito, há uma transformação (Minayo, 2008) e um reajuste de domínios. M passa a se destacar na participação masculina, realizando tarefas tipicamente vistas, ainda hoje, como componentes da maternidade (Lamb, 2010): "Acho que mais por conta dessa questão do orgânico, eu acabei tomando a frente, eu fazia questão... então eu faço as compras até hoje. Desenvolvo o cardápio junto com A e faço a papinha dela. Faço questão!" (M E2).

Os movimentos sociais surgem em oposição ao sistema e mediam as relações do "sujeito" com o mundo (Minayo; Assis; Souza, 2016). Nesta "nova paternidade", o novo é o modo como o pai partilha a afetividade com a criança demonstrando agrado (Sutter; Bucher-Maluschke, 2008) e procurando a sua própria experiência pessoal (Ribeiro; Gomes; Moreira, 2015). "Eu sempre comento com a A, a gente sabe das dificuldades quando você passa por uma fase nova na vida. É lógico, muda a rotina da gente, fica diferente. Mas eu prefiro a de hoje" (M E2).

Nas falas de R(E2), sobressai a experiência paternal adquirida como facilitador no compartilhamento das tarefas (Pérez-Escamilla; Segura-Pérez; Lott, 2017) e que parece repercutir favoravelmente para a incorporação dos novos hábitos do filho (Addati; Cassirer; Gilchrist, 2014).

No início foi difícil, complicado. Eu, na realidade não conhecia muito. Ela (a esposa) foi me explicando: "dá isso, dá aquilo", tanto que quando ele (o filho) chega da escola, ele janta comigo. $\varepsilon$ aí ele começou a introdução até um pouco melhor e foi se soltando, e ele está mandando muito bem! (R E2)

De forma geral, apesar de ambos trabalharem, ainda é da mãe o maior número de afazeres (Parker; Wang, 2013). Os esforços por uma equidade de gênero se concentram, entre outras, em duas questões imbricadas: o mercado de trabalho e a vida familiar (Vega-Robles, 2007).Assim, vemos que os movimentos feministas dos séculos XIX e XX parecem não ter trazido mudanças significativas para os padrões familiares (Hakim, 2005). Teria a maternidade, pelo seu valor como prática social (Minayo; Assis; Souza, 2016) ou por suas características biológicas e psicossociais do vínculo mãe-filho, um peso decisivo em tudo isso (Szinovacz, 1984)? 
Quem faz a listinha é a mamãe, e eu (marido) vou no mercado comprar as coisas. Quem cozinha é a mamãe, no final de semana e no meio da semana, porque nossa vida é bem corrida. Eu só tenho o dever de pegar, descongelar, colocar no pratinho e dar para ele. No final de semana, às vezes eu dou o almoço, às vezes ela dá; a tarde ele mama o peito e o jantar, quem dá mais é ela, porque aí eu já estou fazendo outras coisas. ( $\mathrm{R} \mathrm{E2}$ )

Independente das classes socioeconômicas dos dois grupos, observamos, ao longo das falas, que há princípios em comum que os unem, (Minayo, 2008) aqui observados através da vida familiar, que se desenvolve orientada por atitudes e valores igualmente compartilhados tanto pelo homem quanto pela mulher (Vega-Robles, 2007). Refletindo sobre este aspecto, parece-nos que a mudança dos padrões depende da abordagem de inúmeras barreiras não racionais (Dilts; Hallbom; Smith, 1993) circunscritas não somente aos homens, mas também às mulheres (Vega-Robles, 2007).

As falas de V (E1) nos deixam perceber que é orgulhoso em ser o principal mantenedor da casa e que adota a opinião da esposa nas questões que se referem aos cuidados com a filha, nos remetendo mais uma vez aos papeis tradicionais do homem (Sutter; Bucher-Maluschke, 2008) e da mulher (Jablonski, 2010; Parker; Wang, 2013; Figueiredo; Diniz, 2018). Na continuidade, essas expressões simbólicas dialogam com um "novo modelo paterno" (Jablonski, 2010) relatado através da sua participação na rotina familiar, dando-nos conta de que a modernidade é um projeto inacabado, dinâmico e em constante transformação, produto da relação do sujeito com o mundo e das expressões simbólicas que mediam esta relação (Minayo, 2008).

$V E 1$ Quem cuida é a minha esposa. Não, ela (esposa) não trabalha. Cuida dela (a filha) o tempo todo. A respeito das crianças, a gente conversa bastante para ver se um está de acordo com o que o outro pensa. Às vezes tem o conflito de ideias, entendeu? Mas eu procuro sempre observar mais ela, pelo fato de ela ficar mais com a neném do que eu. E ela tem acertado bastante nas escolhas dela. Eu sou bem tranquilo a respeito da criação dela (filha) e a respeito de criação, educação e alimentação, eu não tenho dúvidas de que eu posso deixar a responsabilidade na mão dela.

$V$ E1... Os dois (cozinham), eu e a minha esposa. A maioria das vezes eu procuro só cortar, descascar, limpar e a minha esposa vai e cozinha. Ela organiza a lista e eu vou e compro.

Dia sim, dia não, eu acompanho (as refeições da filha), que são os dias que eu estou de folga.

Nesta mesma linha de pensamento, o caráter visivelmente autoritário das falas de CR (E1) se contrapõe com relatos de compartilhamento (Balancho, 2004). A prática de hábitos e crenças produzidos em uma estrutura social expressam um modo "de ser" (Dilts; Hallbom; Smith, 1993) e que, entretanto, está sujeito à transformação (Minayo, 2008).

CR E1 Na hora da refeição, eu não gosto de televisão, não gosto que ninguém assista TV, não gosto de celular na mesa, nada que atrapalha a refeição. $\varepsilon$ também não gosto de muita conversa na mesa, eu falo bem pouco... porque senão acaba atrapalhando a refeição.

... eu tenho um menino bom, já a menina eu acho ela muita esperta demais. Que não me dê trabalho!

CR E1 Compras: às vezes sou eu, às vezes é a minha esposa, às vezes juntos. Acompanho (a refeição da filha) no almoço, porque na janta eu não estou em casa, mas quase todos os dias que a gente almoça junto, e não só no almoço, quando eu estou em casa, eu acompanho.

Os movimentos sociais, sobretudo as ações dos indivíduos, têm um impacto na sociedade e podem converter-se em catalizadores para uma mudança social (Vega-Robles, 2007; Minayo, 2008). Chamamos a atenção que o envolvimento de CR no trabalho doméstico aqui sinalizado está sendo copiado pelo filho mais velho. Esta sensibilidade poderia ser um possível preditor para interações futuras (Carvalho; Luz, 2009): “(Quem cozinha em casa) [...] às vezes a minha esposa, às vezes sou eu que faço, 
e tem algumas coisas que, às vezes, o menino (filho mais velho) também ele quer fazer, então fica um pouquinho para cada" (CR E2).

\section{Considerações finais}

Ao tentar compreender a vivência e participação masculina na alimentação dos filhos pequenos, tanto sob a ótica feminina quanto sob a sua própria ótica, nos deparamos com a complexidade como se move o fenômeno, fruto de uma rede de interações entre os indivíduos, seus valores e sua relação com o mundo presente.

Apesar de observarmos que o protagonismo do cuidado ainda é da mulher, fato que independe da condição socioeconômica, há um movimento de transformação nas atitudes de compartilhamento e envolvimento dos homens com os filhos e que mereceria ser encorajado. As crianças, para um melhor começo de vida, dependem de uma multiplicidade de estratégias e habilidades, e a participação paterna no processo e cuidados da alimentação dos filhos seria um potencial facilitador para a adoção de práticas positivas.

Neste caminho, um novo desafio se apresenta para os profissionais e serviços de saúde: a sensibilização e preparação das equipes de saúde, incluindo todos os trabalhadores, para perceber, acolher e valorizar a presença masculina, bem como a implementação de orientações, por meio de estratégias próximas à realidade cultural da comunidade, que incluam a participação masculina em círculos de discussão, reflexão, troca de experiências e dúvidas.

Uma teoria generalizável e que poderia ser útil em programas que explorem estratégias facilitadoras para a mudança dos padrões comportamentais de cuidadores é a da necessidade de se ressignificar antigos valores que norteiam as crenças femininas a favor de uma transformação.

Como limitação do estudo, apontamos a impossibilidade de realizar, entre as mulheres, grupos focais com um mesmo número de participantes. Entre os homens, não houve um número mínimo de participantes para a realização de um grupo focal, o que nos revela, de certa forma, o nível de interesse e envolvimento dos homens sobre a alimentação de seus filhos em ambos os contextos socioculturais em que o estudo foi conduzido. Os que aceitaram participar relataram alguma espécie de compartilhamento, favorecendo a participação masculina, o que poderia ser considerado como um viés. Ainda assim, gostaríamos de ratificar que, como preconiza o método, o tamanho das amostras, tanto dos grupos focais quanto das entrevistas, possibilitou o alcance do conjunto de experiências que se pretendia captar, bem como a reincidências das informações e a apreensão de semelhanças e diferenças.

Ainda que seja necessário ampliar esta discussão, trazendo as novas vivências de pais que não se encaixem em padrões heteronormativos, este é o primeiro artigo nacional que trata dos papéis feminino e masculino na alimentação de crianças pequenas. Acreditamos se constitui em caminho de reflexão para os contextos formativos, podendo, desta forma, contribuir na adoção de estratégias e desenvolvimento de programas de educação nutricional que envolvam a participação masculina na alimentação de crianças com idade entre 6 e 12 meses.

\section{Referências}

ABOIM, S. Género, família e mudança em Portugal. In: WALL, K.; ABOIM, S.; CUNHA, V. (Org.). A vida familiar no masculino: negociando velhas e novas masculinidades. Lisboa: Comissão para a Igualdade no Trabalho e no Emprego, 2010. p. 39-66.

ADDATI, L; CASSIRER N; GILCHRIST, K. Maternity and paternity at work: law and practice across the world International. Geneva: International Labour Organization, 2014.

BALANCHO, L. S. F. Ser pai: transformações intergeracionais na paternidade. Análise Psicológica, Lisboa, v. 22, n. 2, p. 377-386, 2004.

BRASIL. Guia alimentar para crianças menores de 2 anos. Brasília, DF: Ministério da Saúde, 2019.

CARVALHO, M. C. V.; LUZ, M. T. Práticas de saúde, sentidos e significados construídos: instrumentos teóricos para sua interpretação. Interface, Butucatu, v. 13, n. 29, p. 313-326, 2009. DOI: $10.1590 / \mathrm{S} 1414-32832009000200006$ 
DILTS, R.; HALLBOM, T.; SMITH, S. Crenças: caminhos para a saúde e o bem-estar. São Paulo: Summus, 1993.

FIGUEIREDO, M. G.; DINIZ, G. R. S. Mulheres, casamento e carreira: um olhar sob a perspectiva sistêmica feminina. Nova Perspectiva Sistêmica, São Paulo, n. 6o, p. 100-119, 2019.

FREITAS, W. M. F.; COELHO, E. A. C.; SILVA, A. T. M. Sentir-se pai: a vivência masculina sob o olhar de gênero. Cadernos de Saúde Pública, Rio de Janeiro, v. 23, n. 1, p. 137-145, 2007. DOI: 10.1590/ So102-311X2007000100015

HAKIM, C. Modelos de família en las sociedades modernas: ideales y realidades. Madrid: Centro de Investigaciones Sociológicas, 2005.

JABLONSKI, B. O cotidiano do casamento contemporâneo: a difícil e conflitiva divisão de tarefas e responsabilidades entre homens e mulheres. Psicologia, Ciência e Profissão, Rio de Janeiro, v. 3o, n. 2, p. 262-275, 2010.

JAIME, P. C. et al. Assistência em saúde e alimentação não saudável em crianças menores de dois anos: dados da Pesquisa Nacional de Saúde, Brasil, 2013. Revista Brasileira de Saúde Materno Infantil, Recife, v. 16, n. 2, p. 159-167, 2016. DOI: $10.1590 / 1806-93042016000200005$

LAMB, M. E. The role of the father in the child development. 5. ed. New York: John Wiley \& Sons, 2010.

MACK, N. Qualitative research methods: a data collector's field guide. Durham: Family Health International, 2011.

MINAYO, M. C. S. Abordagens metodológicas das ciências sociais aplicadas à saúde: hermenêuticadialética como caminho do pensamento social. In: MINAYO, M. C. S.; DESLANDES, S. F. (Org.). Caminhos do pensamento: epistemologia e método. Rio de Janeiro: Fiocruz; 2008. p. 82-108.

MINAYO, M. C. S.; ASSIS, S. G.; SOUZA, E. R. (Org.). Avaliação por triangulação de métodos: abordagem de programas sociais. Rio de Janeiro: Fiocruz; 2016.

MINAYO, M. C. S. A amostragem e saturação em pesquisa qualitativa: consenso e controvérsias.
Revista Pesquisa Qualitativa, São Paulo, v. 5, n. 7, p. 1-12, 2017.

PARKER, K.; WANG, W. Modern parenthood. Washington, DC: Pew Research Center, 2013.

PÉREZ-ESCAMILLA, R.; SEGURA-PÉREZ, S.; LOTT, M. Feeding guidelines for infants and young toddlers: a responsive parenting approach. Durham: Healthy Eating Research, 2017.

PÉREZ-ESCAMILLA, R.; SEGURA-PÉREZ, S. La alimentación perceptiva en el contexto del marco mundial del cuidado cariñoso y sensible durante la primera infancia. In: UNICEF. Infancia, adolescencia y juventud: oportunidades claves para el desarrollo, Montevideo: 2019. p. 41-65.

RIBEIRO, C. R.; GOMES, R.; MOREIRA, M. C. N. A paternidade e a parentalidade como questões de saúde frente aos rearranjos de gênero. Ciência e Saúde Coletiva, Rio de Janeiro, v. 20, n. 11, p. 3589-3598, 2015. DOI: 10.1590/1413812320152011.19252014

SORRENTINO, E.; VENANCIO, S. I. Conhecimentos e práticas dos pais de crianças de 6 a 12 meses sobre alimentação complementar: desafios para o cuidado em saúde. Demetra, Rio de janeiro, v. 14, p. e43550, 2019.

SUTTER, C.; BUCHER-MALUSCHKE, J. S. N. F. Pais que cuidam dos filhos: a vivência masculina na paternidade participativa. Psico, Porto Alegre, v. 39, n. 1, p. 4-82, 2008.

SZINOVACZ, M. Changing family roles and interactions. In: HESS, B.; SUSSMAN, M. B. Women and the family: two decades of change. London: The Haworth Press, 1984. p. 163-201.

UNICEF - UNITED NATIONS INTERNATIONAL CHILDREN'S EMERGENCY FUND. Crianças, alimentação e nutrição: crescendo saudável em um mundo em transformação. New York: 2019.

UNICEF - UNITED NATIONS INTERNATIONAL CHILDREN'S EMERGENCY FUND. Improving young children's diets during the complementary feeding period. New York: 2020.

USAID - UNITED STATES AGENCY FOR INTERNATIONAL DEVELOPMENT. Behavior change 
interventions and child nutritional status: evidence from the promotion of improved complementary feeding practices. Washington, DC: 2011.

VEGA-ROBLES, I. Relaciones de equidad entre hombres y mujeres. Actualidades en Psicología, San José, v. 21, p. 59-78, 2007.

VICTORA, C. G. et al. Breastfeeding in the 21st century: epidemiology, mechanisms, and lifelong effect. The Lancet, Amsterdam, v. 387, n. 10017, p. 475-49o, 2016. DOI: 10.1016/So140-6736(15)01024-7 WHO - WORLD HEALTH ORGANIZATION. Infant and young child feeding: model chapter for textbooks for medical students and allied health professionals. Geneva: 2010.

ZAGURY, T. Educar sem culpa: a gênese da ética. 18. ed. Rio de Janeiro: Record, 2002.

\section{Contribuição dos autores}

Sorrentino contribuiu com a concepção do projeto, produção e análise de dados e a redação do artigo. Bógus e Venancio contribuíram com a revisão crítica relevante ao conteúdo intelectual e aprovação final da versão a ser publicada, além disso, Venancio orientou a concepção do projeto e análise de dados.

Recebido: 09/02/2021

Reapresentado: 09/02/2021

Aprovado: 18/03/2021 